\title{
Aspirin does not improve early arterial patency after streptokinase treatment for acute myocardial infarction
}

R M Norris, H D White, D B Cross, K S Woo, A H Maslowski, M P Caruana, H H Hart, Barbara Williams

\begin{abstract}
Objective-To investigate the hypothesis that the magnitude of the life saving effect of aspirin in the second international study of infarct survival (ISIS-2) trial cannot be explained solely by prevention of late reocclusion of the infarct related artery. The aim of this study was to discover whether or not aspirin in combination with streptokinase had an adjuvant thrombolytic effect.

Design-Aspirin (150 mg) or placebo was given at the start of streptokinase infusion to 200 patients seen within six hours of the start of prolonged ischaemic cardiac pain and ST segment elevation. All patients received active aspirin at three hours. Patency of the infarct related artery was assessed non-invasively by the normalised rise of creatine kinase activity at three hours after starting streptokinase in these 200 patients and in a further 52 patients who had already taken aspirin within one week of the start of infarction.
\end{abstract}

Main outcome measure-Rise in creatine kinase activity from baseline to $\geqslant 20 \%$ or $<20 \%$ of the peak rise of activity in blood taken at three hours after starting infusion of streptokinase. This correlates with patency or occlusion of the infarct related coronary artery at about 2.5 hours after starting streptokinase.

Results-Assessed in this way, patency of the infarct related artery was $60 \%$ in patients given aspirin, $63 \%$ in those given placebo, and $62 \%$ in patients who had already taken aspirin within one week of infarction.

Conclusion-The magnitude of the life saving effect of aspirin remains unexplained. Further investigation is needed into the mechanism of action of antiplatelet treatment in relation to thrombolytic treatment.

(Br Heart f 1993;69:492-495)

Thrombolytic treatment is life saving after acute myocardial infarction ${ }^{12}$ by causing recanalisation of the infarct related coronary artery leading to reperfusion of the developing infarct. The second international study of infarct survival (ISIS-2) trial showed that aspirin reduced mortality by almost as much as streptokinase and that the reduction was as great for patients who did not receive strep- tokinase (about 25 lives saved/1000 patients treated) as for those who did. ${ }^{2}$ It is widely believed that aspirin prevents late reocclusion of the infarct related coronary artery once $\mathbb{\otimes}$ recanalisation has occurred. In favour of this are the findings that aspirin prevented reinfarction but did not influence infarct size, ${ }^{3}$. and that it prevented cardiac death and $\vec{\omega}$ infarction, presumably caused by arterial o occlusion, in patients with unstable angina. ${ }^{45}$ The magnitude of the benefit from aspirin in 8 the ISIS-2 trial points against such a role as the sole benefit from aspirin; reinfarction in $\overrightarrow{0}$ the first month occurs in only $3 \%-4 \%$ of $N$ patients after thrombolytic treatment without aspirin ${ }^{26}$ and was fatal in the ISIS-2 trial in $\vec{c}$ $0.9 \%$ with aspirin and in $1.3 \%$ without. $^{2}$ Reduction of mortality by aspirin in ISIS- 2 for patients given streptokinase was about six times greater than could be explained by reduction of fatal reinfarction.

Our study was designed to assess whether addition of aspirin in the dose that was used in the ISIS-2 trial $^{2}$ was associated with early patency of the infarct related artery in more $\triangle$ cases than if aspirin was temporarily with- $\overrightarrow{\overrightarrow{0}}$ held. Arterial patency was assessed non-invasively by measurement of the normalised rise of creatine kinase activity after infusion of streptokinase. The sensitivity, specificity, and $\vec{\sigma}$ prognostic implications of patency assessed $\cong$ by this method have been documented separately. ${ }^{7}$

Patients and methods

All patients under 76 years of age presenting within six hours of the start of prolonged ischaemic chest pain and ST segment eleva- $N$ tion in at least two leads of the electrocardio- $N$ gram of $\geqslant 1 \mathrm{~mm}$ in leads II, III, AVF, or $\mathrm{N}$ $\mathrm{V}_{4}-\mathrm{V}_{6}$, and $\geqslant 2 \mathrm{~mm}$ in $\mathrm{V}_{1}-\mathrm{V}_{3}$ were considered ${ }_{\sigma}^{\omega}$ for entry to the study provided that there were no contraindications to giving strepto- $\stackrel{O}{C}$ kinase. Patients were asked about aspirin $\stackrel{\mathscr{\Phi}}{\rightarrow}$ ingestion. Those who had not taken aspirin or 0 compounds containing aspirin within the previous week and who were not intolerant of $\stackrel{\vec{\Omega}}{\Omega}$ aspirin were asked to chew a half tablet that $\overrightarrow{\mathbb{D}}$ contained either aspirin $(150 \mathrm{mg})$ or placebo $\bar{\sigma}$ immediately before the start of an infusion of $1.5 \times 10^{6}$ units of streptokinase given over 30-60 minutes. Aspirin or placebo were randomised in blocks of eight, and the study was double blind.

At the start of the streptokinase infusion, at hourly intervals for four hours, and then at four hourly intervals for 24 hours after strep- 
tokinase, $5 \mathrm{ml}$ of blood was taken from the intravenous line for measurement of plasma total creatine kinase activity by the Rosalki method. ${ }^{8}$ The rise of enzyme activity from the baseline at three hours after streptokinase was expressed as a proportion of the peak rise in activity from baseline. A proportion of $\geqslant 20 \%$ at three hours was taken as evidence for early reperfusion. ${ }^{7}$ At three hours after starting streptokinase, aspirin $(150 \mathrm{mg}$ ) was given to all patients and this dose was continued daily. Patients who had already taken aspirin also had enzyme activities measured.

In a separate project (still in progress) patients in the present study with first infarction who were not taking angiotensin converting enzyme inhibitors were enrolled in a post infarction trial of oral captopril $v$ placebo with angiocardiography at three weeks for determination of left ventricular volumes and ejection fraction according to our previously described protocol. ${ }^{9}$ Patency of the infarct related coronary artery (identified from electrocardiographic and wall motion changes) was assessed by the thrombolysis in myocardial infarction (TIMI) criteria. ${ }^{10}$ A TIMI grade 2 or 3 was taken to indicate patency. Patients gave informed consent for these studies that were approved by the ethics committees at Green Lane, Middlemore, and North Shore Hospitals.

Differences between categorical values were assessed by the $\chi^{2}$ test with Yates correction and between continuous variables by use of the paired $t$-test. Power calculations indicated that we would need 164 randomised patients to show an improvement in early infarct artery patency from $60 \%$ to $80 \%$ from aspirin with an $\alpha$ error (two sided) of 0.05 and a $\beta$ error of $0 \cdot 2$.

\section{Results}

Two hundred and fifty six patients had serial measurements of enzyme activity for non invasive diagnosis of reperfusion. Of these, 200 had not taken aspirin and were entered

Table 1 Patient characteristics at entry and during the three hour trial period

\begin{tabular}{|c|c|c|c|}
\hline & $\begin{array}{l}\text { Aspirin } \\
(n=95)\end{array}$ & $\begin{array}{l}\text { Placebo } \\
(n=105)\end{array}$ & $\begin{array}{l}\text { Previous aspirin } \\
(n=52)\end{array}$ \\
\hline $\begin{array}{l}\text { Mean (SD) age (yr) } \\
\text { Men }(\%)\end{array}$ & $\begin{array}{l}58(10) \\
75\end{array}$ & $\begin{array}{l}60(10) \\
80\end{array}$ & $\begin{array}{l}58(9) \\
75\end{array}$ \\
\hline $\begin{array}{l}\text { Mean (SD) time from start of pain to } \\
\text { streptokinase infusion (L) } \\
\text { Previous infarction (\%) } \\
\text { Anterior infarction (\%) } \\
\text { Concomitant heparin treatment (\%) }\end{array}$ & $\begin{array}{l}2 \cdot 8(1 \cdot 3) \\
9 \\
46 \\
8\end{array}$ & $\begin{array}{l}3 \cdot 2(1 \cdot 3) \\
11 \\
40 \\
9\end{array}$ & $\begin{array}{l}3 \cdot 2(1 \cdot 3) \\
6 \\
33 \\
17\end{array}$ \\
\hline
\end{tabular}

Table 2 Enzymic and angiocardiographic indicators (mean (SEM) of infarct related arterial patency and infarct size

\begin{tabular}{lccc}
\hline & $\begin{array}{c}\text { Aspirin } \\
(n=95)\end{array}$ & $\begin{array}{c}\text { Placebo } \\
(n=105)\end{array}$ & $\begin{array}{c}\text { Previous aspirin } \\
(n=52)\end{array}$ \\
\hline Enzymatic indices: & & & \\
CK >20\% at 3 $\mathrm{h}$ & $57(60 \%)$ & $66(63 \%)$ & $32(62 \%)$ \\
Peak CK (mIU/ml) & $2769(214)$ & $2636(183)$ & $3060(309)$ \\
Time to peak CK (h) & $12 \cdot 2(0 \cdot 5)$ & $12 \cdot 3(0 \cdot 6)$ & $12 \cdot 4(0 \cdot 9)$ \\
CK integrated appearance function (IU/ml) & $4 \cdot 0(0 \cdot 3)$ & $3 \cdot 9(0 \cdot 3)$ & $4 \cdot 3(0 \cdot 5)$ \\
Angiocardiographic indices assessed at three weeks: & & \\
Patency of the infarct related artery & $50 / 71(70 \%)$ & $54 / 75(72 \%)$ & $30 / 39(77 \%)$ \\
Ejection fraction (\%) & $58(1)$ & $57(1)$ & $56(2)$ \\
End systolic volume (ml) & $71(4)$ & $65(4)$ & $66(4)$ \\
\hline
\end{tabular}

CK, creatine kinase. into the randomised trial (aspirin 95, placebo 105), whereas 52 had taken aspirin within the previous week, usually given in the Emergency department after the start of symptoms of infarction. Four patients were not given aspirin because of a history of aspirin intolerance. Of the 256 patients, 53 were included in the validation study ${ }^{7}$ and had angiocardiograms at $2 \cdot 6(0.3)$ hours after thrombolysis, whereas 185 were in the captopril trial and had angiocardiograms at three weeks after infarction. The disparity in numbers between aspirin and placebo (95 $v 105$ ) is explained by the fact that the aspirin or placebo and captopril or placebo were included in the same numbered packets, the aspirin or placebo being discarded for patients who were included in the captopril trial but who had already taken aspirin. By chance, more active aspirin than placebo tablets had been discarded.

Table 1 shows patient characteristics at entry and during the three hour study period. Patients were evenly matched for age, sex, and time between the start of symptoms and being given streptokinase. Twenty seven patients had heparin infusion during the three hour study period, usually starting after completion of the streptokinase. After completion of the study, 12 patients died in hospital (mortality rate $5 \%$ ); of these five had aspirin, five had placebo, and two had already taken aspirin. Thirteen (5\%) patients had reinfarction while in hospital.

Table 2 shows enzymic and angiocardiographic indices of patency of the coronary artery and infarct size in patients given aspirin or placebo and in those already taking aspirin. There was no difference in the proportion of patients showing a rise in creatine kinase activity at three hours of $\geqslant 20 \%$ of peak, nor in the mean time to peak activity, the peak activity, or the creatine kinase integrated appearance function of enzyme release, which is a measure of infarct size. ${ }^{112}$ As a further check on the normalised rate of rise of enzyme activity as an index of arterial patency, the proportions of patients showing $\geqslant 20 \%$ of peak activity at two hours and at four hours were also calculated. There were no significant differences (at two hours aspirin $39 \%$, placebo $41 \%$, previous aspirin $35 \%$; and at four hours aspirin $79 \%$, placebo $75 \%$, previous aspirin $71 \%$ ). Also, the figure shows the mean (SEM) proportions of peak activity that were calculated for each sampling period up to 12 hours. This shows a similar pattern of normalised rate of enzyme release for all three groups.

There were also no differences in the angiocardiographic indices among the three groups of patients. Patency of the infarct related coronary artery judged from the three week angiograms was higher than the early indirectly assessed patency, suggesting that more arteries had shown late recanalisation than had undergone late reocclusion. Neither late arterial patency, ejection fraction, nor end systolic volume differed with or without early aspirin. 


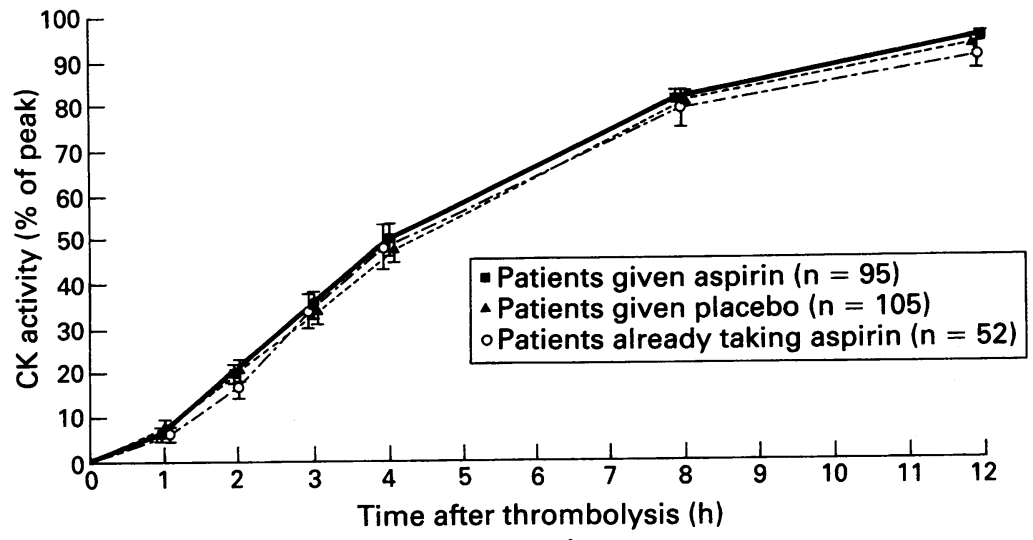

Mean (SEM) creatine kinase (CK) activity after administration of aspirin (150 mg) or placebo, at the start of streptokinase infusion. All patients were given active aspirin at three hours. late, or no reperfusion as judged by coronary arteriography. ${ }^{7}$ Moreover there were no differences among the groups in any of the other enzymatic or angiocardiographic indices of reperfusion or of myocardial infarct size.

The enzymatic method that we used for non-invasive determination of arterial patency 0 has been validated in 60 patients in whom ${ }_{I}$ angiographic patency at $2.6(0.3)$ hours was compared with the normalised rate of rise of creatine kinase activity at three hours after the starting of thrombolytic treatment. ${ }^{7}$ In this $\overrightarrow{\overrightarrow{\vec{F}}}$ study the rise in activity from the start of streptokinase infusion to three hours after-듬 wards was $>20 \%$ of the total rise to peak $\frac{\bar{c}}{\sigma}$ activity in $34 / 37(92 \%)$ of patients in whom $\stackrel{\varnothing}{\varnothing}$ the infarct related artery was patent at arteriography. The rise was $<20 \%$ of peak in $21 / 23$, $(91 \%)$ of those in whom the artery was. occluded. Sensitivity for the test would likely $\vec{\omega}$ have been higher than $92 \%$ in this study if allowance could have been made for the lag? period between reperfusion and enzymes washout.

Although the total results of ISIS-2 sug-e gested that benefits from aspirin and strep- -0 tokinase were independent of each other, subsequent analysis showed that for patientsc treated within five hours of the start (similar to those in our study) there was a significant interaction between the two agents. ${ }^{1718}$ Odds 8 of dying were reduced by $47 \%$ by streptoki- $\omega$ nase in the presence of aspirin but by onlyo $26 \%$ by streptokinase in the absence of aspirin; for patients treated between five andō 24 hours from the start the interaction was in the opposite direction.

This analysis would support an adjuvant $\overrightarrow{\overrightarrow{0}}$ thrombolytic action of aspirin, as we postula- 3 ted, for patients treated early. Our findings however, provide no evidence for this. Although the dose of aspirin $(150 \mathrm{mg})$ was $\bar{\alpha}$ small and we do not know the time after the start of thrombolytic treatment at which effective concentrations were achieved, the drug was given in the same way (crunched in the mouth) and in a similar dose $(150 \mathrm{mg} v$ $162.5 \mathrm{mg}$ ) to that used in the the ISIS-2 trial.o Our study pertains only to the first three hours after giving streptokinase, because we thought it unethical to withold aspirin for o longer than this. Early platelet induced silentru reocclusion could occur later (say between three and 24 hours) and a protective effect of aspirin during this time is not excluded. Also not excluded is the possibility that variations? in cyclical flow might be inhibited by aspirin, as has been shown experimentally. ${ }^{16}$ Ouro enzymatic method $^{7}$ relates mainly to restoration of sustained TIMI 3 patency and inter $-\Omega$ mittent partial reperfusion might be $\vec{\Omega}$ undetected. Moreover our size calculations were based on an expected increase from $60 \%$ to $80 \%$ in patency of the infarct relatedo artery a smaller increase, say from $60 \%$ to․ㅡ. $70 \%$, is not excluded.

Aspirin was shown to prevent reinfarction over a three month period in a group of 100 patients, half of whom received thrombolytic treatment, ${ }^{3}$ and to reduce the incidence of a 
combined end point of death, reinfarction, and the need for angioplasty or surgery in 300 patients from three days to three months after streptokinase. ${ }^{19}$ These beneficial effects no doubt resulted from prevention of late reocclusion of the infarct related coronary artery. As already noted, however, the size of the reduction in mortality from aspirin is too large to be explained solely by reduction in mortality from reinfarction, or indeed from silent reocclusion of the infarct related coronary artery. ${ }^{20}$

These considerations make it difficult to accept that the magnitude of the effect of aspirin in the ISIS-2 trial can be attributed solely to prevention of reocclusion of the coronary artery. Moreover the present finding, subject to the limitations discussed, provide no evidence for an adjuvant thrombolytic effect. Some different action of aspirin might be postulated, ${ }^{2122}$ but no effect on infarct size assessed by enzyme release was apparent either in our study or in one of the earlier trials that showed prevention of reinfarction by aspirin. ${ }^{3}$ Further clinical trials are needed to explore the mechanism of action of anti platelet drugs, and of aspirin in particular, in relation to thrombolytic treatment in patients.

We thank the nursing staff in the coronary care units at al three hospitals for their help with this trial. Aspirin and placebo were supplied by Glaxo Group Research, Greenford, Middlesex, UK. We are grateful to Mrs Carol Caunter for typing the paper.

1 GISSI Trial Group. Effectiveness of intravenous thrombolytic treatment in acute myocardial infarction. Lancet 1986;i:397-401.

2 Second international study of infarct survival (ISIS-2) Collaborative Group. Randomised trial of intravenous streptokinase, oral aspirin, both, or neither amon 17187 cases of suspected acute myocardial infarction. ISIS-2. Lancet 1988;2:349-59.

3 Verheugt FWA, van der Laarse A, Funke-Kupper AJ, Sterkman LGW, Galema TW, Roos JP. Effects of early Sterkman LGW, Galema TW, Roos JP. Effects of early intervention with low dose aspirin (100 mg) on infarct size, reinfarction, and mortality in anterior wall ac

4 Lewis HD, Davis JW, Archibald DG, et al. Protective effects of aspirin against acute myocardial infarction and effects of aspirin against acute myocardial infarction and death in men with
$1983 ; 309: 396-403$
5 Cairns JA, Gent M, Singer J, et al. Aspirin, sulfinpyrazone or both in unstable angina. $N$ Engl $f$ Med 1985;313:1369-75.

6 Rivers JT, White HD, Cross DB, Williams BF, Norris RM. Reinfarction after thrombolytic therapy for acute myocardial infarction followed by conservative management: incidence and effect of smoking. $₹ \mathrm{Am}$ Coll ment: incidence and

7 Norris RM, White HD, Cross DB, Woo KS, Elliott JM Twigden $\mathrm{D}$, et al. Noninvasive diagnosis of arterial patency after thrombolytic therapy and its relationship to prognosis. Br Heart f 1993;69:485-91.

8 Rosalki SB. An improved method for creatine phosphokinase determination. F Lab Clin Med 1967;69:696-705.

9 White HD, Norris RM, Brown MA, et al. Effect of intravenous streptokinase on left ventricular function and early survival after acute myocardial infarction. $N$ Engl $\mathcal{F}$ Med 1987;317:850-5.

10 Chesebro JH, Knatterud G, Roberts $\mathrm{R}$, et al. Thrombolysis in myocardial infarction (TIMI) trial, phase I: a comparison between intravenous tissue plasminogen activator and intravenous streptokinase. Circulation 1987;76:142-54.

11 Sobel BE, Bresnahan GF, Shell WE, Yoder RD. Estimation of infarct size in man and its relation to prognosis. Circulation 1972;46:640-8.

12 Norris RM, Whitlock RML, Barratt-Boyes $C$, Small CW. Clinical measurement of myocardial infarct size: modification of a method for the estimation of total creatine cation of a method for the estimation of total creatine phosphokinase release after

13 Coller BS. Platelets and thrombolytic therapy. $N$ Engl $\mathcal{J}$ Med 1990;322:33-42.

14 Fitzgerald DJ, Catella F, Roy L, Fitzgerald GA. Marked platelet activation in vivo after intravenous streptokinase in patients with acute myocardial infarction. Circulation 1988;77:142-50.

15 Hackett D, Davies G, Chierchia S, Maseri A. Intermittent coronary occlusion in acute myocardial infarction. Value of combined thrombolytic and vasodilator therapy. $N$ Engl f Med 1987;317:1055-9.

16 Gold HK, Coller BS, Yasuda T. Rapid and sustained coronary artery recanalization with combined bolus injection of recombinant tissue-type plasminogen activator and monoclonal antiplatelet GPIB/IIIA antibody in a canine preparation. Circulation 1988;77:670-7.

17 Basinski A, Naylor CD. Aspirin and fibrinolysis. Lancet 1988;2:1188-9.

18 Basinski A, Naylor CD. Aspirin and fibrinolysis in acute myocardial infarction: meta-analytic evidence for synergy. F Clin Epidemiol 1991;44:1085-96.

19 Meijer A, Werter CJ, Verheugt FWA, Lie KI, van der Pol JMJ, Michels HR. The APRICOT study: aspirin versus coumadin in the prevention of recurrent ischemia and reocclusion after successful thrombolysis, a placebocontrolled angiographic follow-up study. $9 \mathrm{Am} \mathrm{Coll}$ Cardiol 1992;19:91A.

20 Roux S, Christeller S, Ludin E. Effects of aspirin on coronary reocclusion and recurrent ischemia after thrombolysis: reccluming

1 Ruy W, Sulino GT, Sulkiro A Cardiol 1992,19:671-7. mocardial blood flow in A McNamara JJ. Regional experimental myocardia infarction after pretreatment with aspirin. $\mathcal{F} \mathrm{Am}$ Coll

22 Moschos CB, Haider B, De La Cruz C, Lyons MM Regan TJ. Antiarrhythmic effects of aspirin during nonthrombotic coronary occlusion. Circulation $1978 ; 57: 681-4$ 